\title{
TINGKAT KESUKAAN BEBERAPA BAHAN PAKAN BURUNG NURI TALAUD (Eos histrio) DAN PERFORMANS YANG DIPELIHARA SECARA EX-SITU
}

\author{
Anna M. Bella, H. J. Kiroh *, Meis J. Nangoy, Martha M. H. Kawatu, James R. M. \\ Keintjem
}

Fakultas Peternakan Universitas Sam Ratulangi Manado, 95115

\begin{abstract}
ABSTRAK
Eos histrio adalah burung nuri endemik pulau-pulau yang berada di bagian Utara Pulau Sulawesi. Burung ini di habitatnya dikenal dengan nama Burung Sampiri dan secara internasional sebagai Red and Blue Lory atau Blue Tailed Lory berharga jual tinggi, oleh karena itu penangkapan burung ini di habitatnya tinggi. Perlu adanya pelestarian intensif dan pengembangan teknik konservasi ex situ. Penelitian ini bertujuan untuk mengetahui dan mengamati tingkat kesukaan, pertambahan berat badan, konsumsi pakan Burung Nuri Talaud (Eos histrio) yang dipelihara secara Ex-situ, berlokasi di Balai Konservasi Sumber Daya Alam (BKSDA) Sulawesi Utara selama 1 (satu) bulan dengan menggunakan Metode Deskriptif dan penyajian dalam bentuk tabel, grafik dan gambar pada 2 (dua) ekor burung yang terdiri dari 1 (satu) jantan dan 1 (satu) betina. Dari hasil penelitian diperoleh bahwa bahan pakan burung yang paling disukai oleh burung jantan maupun betina yaitu jagung, pepaya, pisang dan semangka. Konsumsi bahan pakan paling banyak ditemukan pada burung betina. Demikian juga pertambahan berat badan pada burung betina.
\end{abstract}

Kata kunci: Burung Nuri Talaud (Eos histrio), Ex-Situ, Tingkat Kesukaan, Konsumsi Bahan Pakan, Pertambahan Berat Badan.

\footnotetext{
*Korespondensi (Corresponding Author) Email: wakilrektor3_hk@yahoo.com
}

\begin{abstract}
THE LEVEL OF THE FEED INGREDIENTS ARE FAVORITES OF BIRDS PARROTS TALAUD ISLANDS (EOS HISTRIO) AND PERFORMANS PRESERVED IN EX-SITU. Eos histrio is a parrot endemic to islands that are located in the northern part of the island of Sulawesi. This bird in its Habitat the bird known as the Sampiri, and internationally as Red and Blue Lory Lory, On trading of birds, birds have a high selling price, therefore catching the bird in its Habitat, the need for more intensive conservation efforts and need to be developed the techniques of ex situ conservation. This research aims to know and observe the level of fondness, feed consumption and added weight Birds Parrot Talaud Islands (Eos histrio) preserved in Ex-situ. This research was carried out in natural resources Conservation (BKSDA) North Sulawesi in 1 (one) month. The animals examined i.e. 2 birds talaud Lory (Eos histrio) in males and females. The observed variable the level of fondness, consumption, efficiency of feed materials and weight added. This research by using descriptive method and presented in the form of tables. From the results obtained that the level of the feed ingredients are favorites of birds parrots talaud Islands (Eos histrio) in males as well as females, namely corn, papaya, bananas and watermelon, the consumption of feed and added the most weight in female.
\end{abstract}

Keywords: Bird Parrot Talaud Islands (Eos histrio), Ex-Situ, Level of Fondness, Added Weight, Consumption. 


\section{PENDAHULUAN}

Eos histrio adalah burung nuri endemik pulau-pulau yang berada di bagian Utara Pulau Sulawesi. Burung ini di habitatnya dikenal dengan nama Burung Sampiri dan secara internasional sebagai Red and Blue Lory atau Blue Tailed Lory, karena bulunya berwarna merah dan biru mencolok. Menurut Coates dan Bishop (2000), burung ini terdiri dari tiga subspecies yaitu E.h. histrio yang ditemukan di Kepulauan Sangihe, E.h talautensis di Kepulauan Talaud, serta E.h. callengeri di Pulau Miangas dan Kepulauan Nanusa. Habitatnya hutan primer, hutan perbukitan, serta kebun kelapa ketinggian $>500 \mathrm{~m}$ dpl. Berdasarkan hasil penelitian (Diah, dkk, 2010) yang mengidentifikasi lokasi, karakter pohon tidur Gehe (Pometia corriaceae Radkl), Binsar (Ficus variegate Blume), War'ro (Duabanga moluccana Blume), dan Lawean (Sterculia sp.). Menurut Lambert (1997), E.h. talautensis adalah spesies yang masih ditemukan di habitatnya.

Selain berwarna bulu menarik dan indah, burung ini bersuara unik sehingga burung ini dipelihara sebagai hewan kesayangan. Dalam perdagangan burung ini bernilai jual tinggi, sehingga penangkapan dan penjualannya tinggi. Di samping itu alih fungsi lahan terjadi di habitatnya sehingga status populasinya
"Terancam (EN)". $\quad$ Perdagangan internasionalnya adalah "Appendix I" yang artinya tidak boleh diperdagangkan selain untuk tujuan khusus seperti riset ilmiah atau sejenisnya.

Semenjak tahun 1920, di Kepulauan Talaud sebagian besar lahan dijadikan perkebunan kelapa, cengkih dan pala. Perubahan ini tentu membawa dampak bagi spesies-spesies satwa yang kehidupannya sangat bergantung pada keberadaan hutan baik sebagai tempat berlindung ataupun tempat mencari pakan. Hal ini berdampak pula penurunan populasinya.

Upaya-upaya peningkatan populasi perlu dilakukan melalui pencegahan penangkapan burung di habitat, pemeliharaan habitat, pendidikan masyarakat tentang peran burung dalam ekosistem, dan usaha penangkaran burung. Menurut Mayasari dan Suryawan (2012), perlu adanya upaya pelestarian intensif dan pengembangan teknik konservasi ex situ. Konservasi ex situ dapat dilakukan melalui penangkaran. Penangkaran merupakan salah satu solusi yang dapat dilakukan menekan laju penurunan populasi burung di alam. Untuk penangkaran diperlukan pengetahuan tentang manajemen, breeding dan feedingnya. Pakan burung merupakan salah satu unsur penting bahkan sebagai faktor pembatas, karena merupakan sumber nutrisi bagi keberlangsungan hidup dan untuk perkembang biakan. Jika terjadi 
defisiensi pakan, maka burung terancam bahkan bisa terjadi kematian.

Burung yang dipelihara di dalam kandang tidak dapat mencari makan dan air minum sendiri. Semua kebutuhan pakan dan air minum harus disediakan oleh pemeliharanya. Pengetahuan jenis pakan utama dan disukai (palatable) burung ini di penangkaran harus diketahui oleh pemeliharanya.

Berdasarkan uraian di atas maka dilakukan penelitian tingkat kesukaan bahan pakan segar burung nuri talaud (Eos histrio) dan performans yang dipelihara secara ex-situ untuk mengetahui jenis bahan pakan utama yang disukai oleh burung.

\section{MATERI DAN METODE PENELITIAN}

Penelitian ini dilaksanakan di Balai Konservasi Sumber Daya Alam (BKSDA) Sulawesi Utara. Waktu penelitian ini berlangsung selama 30 hari pengamatan. Penelitian ini dilakukan pada 2 (dua) ekor burung nuri talaud (Eos histrio) yang terdiri dari satu ekor jantan dan satu ekor betina dengan menggunakan alat-alat sebagai berikut: tenggeran, tempat makan, tempat minum, timbangan, dan kandang berukuran $3 \mathrm{~m} \times 1,5 \mathrm{~m}$ x $2 \mathrm{~m}$ (p x $1 \times \mathrm{t})$. Bahan pakan diberikan selama penelitian yaitu: jagung, pepaya, pisang, semangka, dan madu. Hal- hal yang dikerjakan selama penelitan meliputi: pembersihan kandang yang dilakukan dua kali sehari yaitu pagi dan siang hari, penimbangan pakan, pemberian pakan, dan penimbangan sisa pakan.

Pemberian pakan dilakukan dengan cara sebagai berikut: pada pagi hari diberikan semua jenis pakan dan siang hari dilakukan penggantian pakan kecuali madu. Setiap jenis pakan ditimbang seberat $100 \mathrm{~g}$ dan diberikan pada burung. Penimbangan sisa pakan pagi hari dilakukan pada siang hari sedangkan penimbangan sisa pakan siang hari dilakukan keesokan harinya. Pemberian air minum dilakukan ad libitum yang berarti air minum dijaga agar tidak habis (selalu tersedia). Sebelum masa perlakuan selama 30 hari, terlebih dahulu dilakukan masa preliminary (masa adaptasi) selama enam hari.

Data penelitian seperti tingkat kesukaan diperoleh dari pengamatan jenis bahan pakan yang disukai, selanjutnya untuk konsumsi pakan diperoleh dari penghitungan selisih jumlah berat pakan yang diberikan sebelum dan sesudah konsumsi. Untuk pertambahan berat badan burung diperoleh dari penghitungan berat badan akhir (g/ekor/minggu) dikurangi dengan berat badan awal (g/ekor/minggu). Kemudian data dianalisis secara deskriptif, dan disajikan dalam bentuk Tabel. 


\section{HASIL DAN PEMBAHASAN}

\section{Tingkat Kesukaan}

Hasil pengamatan tingkat kesukaan dari burung nuri talaud diperoleh bahwa tidak ada perbedaan terhadap kelima jenis bahan pakan (Tabel 1). Hal ini menunjukkan bahwa burung nuri menyukai jagung, pepaya, pisang, semangka, dan madu. Di habitatnya, burung nuri talaud memakan buah dan serangga, juga mengkonsumsi kacang, nektar dari bunga kelapa dan tanaman buah di lahan pertanian (Birdlife International, 2013). Lebih lanjut tingkat kesukaan suatu bahan pakan ditentukan oleh bentuk fisik, warna bahan pakan tersebut (Kiroh, 2009). Pada penelitian ini, menunjukkan bahwa bentuk fisik dan warna tidak memberikan pengaruh (Tabel 1).

\section{Konsumsi Bahan Pakan}

Hasil pengamatan konsumsi bahan pakan diperoleh bahwa rata-rata jumlah konsumsi burung betina lebih banyak daripada jantan (Tabel 2). Pada penelitian ini diperoleh juga bahwa konsumsi burung nuri talaud (Eos histrio) lebih banyak pada bahan pakan segar dalam bentuk padat dibandingkan dengan bentuk cair yang ditunjukkan oleh jumlah konsumsi jagung, pepaya, pisang, semangka dalam bentuk padat rata-rata 105-140 g sedangkan ratarata madu 70-105 g. Kurangnya konsumsi madu karena madu mengandung energi 304 kkal yang lebih tinggi dari pada keempat bahan pakan lainnya. Konsumsi pakan dapat dipengaruhi oleh berbagai faktor antara lain kandungan gizi dalam pakan antara lain umur, palatabilitas, kesehatan, jenis burung, aktivitas burung (Hernandez et al., 2004; Fan et al., 2008; Nuraini et al. 2012). Rata-rata konsumsi pakan burung

Tabel 1. Tabel Kesukaan Bahan Pakan Segar Berdasarkan Warna dan Bentuk Fisik

\begin{tabular}{|c|c|c|c|c|c|c|c|}
\hline \multirow{2}{*}{$\begin{array}{l}\text { Bahan } \\
\text { Pakan } \\
\text { Segar }\end{array}$} & \multicolumn{2}{|r|}{ Warna } & \multicolumn{3}{|c|}{ Bentuk Fisik } & \multicolumn{2}{|c|}{ Jenis Kelamin } \\
\hline & Kuning & Kuning-Oranye & Merah & Padat & Cair & Jantan & Betina \\
\hline Jagung & $\sqrt{ }$ & & & $\sqrt{ }$ & & $\sqrt{ }$ & $\sqrt{ }$ \\
\hline Pepaya & & $\sqrt{ }$ & & $\sqrt{ }$ & & $\sqrt{ }$ & $\sqrt{ }$ \\
\hline Pisang & $\sqrt{ }$ & & & $\sqrt{ }$ & & $\sqrt{ }$ & $\sqrt{ }$ \\
\hline Semangka & & & $\sqrt{ }$ & $\sqrt{ }$ & & $\sqrt{ }$ & $\sqrt{ }$ \\
\hline Madu & $\sqrt{ }$ & & & & $\sqrt{ }$ & $\sqrt{ }$ & $\sqrt{ }$ \\
\hline
\end{tabular}


Tabel 2. Konsumsi Bahan Pakan

\begin{tabular}{ccc}
\hline Bahan Pakan & \multicolumn{2}{c}{ Rataan Jumlah Konsumsi $(\mathrm{g} / \mathrm{minggu})$} \\
\cline { 2 - 3 } & Jantan & Betina \\
\hline Jagung & 105 & 140 \\
Pepaya & 105 & 140 \\
Pisang & 105 & 140 \\
Semangka & 105 & 140 \\
Madu & 70 & 105 \\
\hline
\end{tabular}

Tabel 2. Berat Badan Awal dan Berat Badan Akhir

\begin{tabular}{ccccc}
\hline No. & & Berat Badan Awal & Berat Badan Akhir & $\begin{array}{c}\text { Pertambahan Berat } \\
\text { Badan/g/ekor/hari }\end{array}$ \\
\hline 1. & Jantan & $142 \mathrm{~g}$ & $170 \mathrm{~g}$ & 0,933 \\
2. & Betina & $151 \mathrm{~g}$ & $215 \mathrm{~g}$ & 2,133 \\
\hline
\end{tabular}

nuri talaud (Eos histrio) yang berukuran sedang dapat mencapai 100 g/ekor/hari (Prijono dan Handini, 1998).

\section{Pertambahan Berat Badan}

Hasil pengamatan pertambahan berat badan diperoleh bahwa berat badan burung betina lebih berat daripada jantan (Tabel 3). Perbedaan pertambahan berat badan jantan dan betina merupakan korelasi dari aktivitas harian burung nuri, pada jantan yang dipelihara secara individu lebih aktif bersiul, melompat, jalan dan terbang sedangkan pada betina hanya banyak berdiam di tenggeran sambil membersihkan tubuh. Menurut Campbell (1996) bahwa bobot badan dipengaruhi oleh kualitas pakan, kemampuan ternak untuk mengubah menjadi daging, keseimbangan pakan, ukuran tubuh, temperatur lingkungan, berat hidup, bentuk fisik pakan dan jenis kelamin.

\section{KESIMPULAN}

Berdasarkan hasil pengamatan yang diperoleh bahwa tingkat kesukaan burung nuri talaud (Eos histrio) terhadap jagung, pepaya, pisang, semangka, dan madu tidak ada perbedaan atau sama dan rata-rata jumlah konsumsi burung betina lebih banyak daripada jantan, serta pertambahan berat badan burung betina lebih berat daripada jantan.

\section{DAFTAR PUSTAKA}

Birdlife International. (2013). Eos histrio. The IUCN red list of threatened 
species 2013. Diunduh 26 May 2016 dari http://dx.doi.org/10.230/IUCN.UK. 20132.RLTS.T22684502A4810703 1.en.

Campbell, L.A., J.G. Hallet, and M.A. O' Connell. 1996. Conservation of Bats in Managed Forest: Use of Roostby Brown Bats. Eptesicus fuscus, Conform to the Fission-Fusion Model. Jurnal Animal Behaviour, No. 68: 495505.

Coates, B.J. dan K.D. Bishop. 2000. Panduan Lapangan Burung-Burung di Kawasan Wallacea. Brisbane, Australia: Birdlife InternationalIndonesia Programme \& Dove Publication Pty. ISBN 979-957942-2.

Diah, I. D. A., P. Satyawan, P. Erny. 2017. Seleksi Pohon Tidur Burung Nuri Talaud (Eos histrio Muller,1776) Di Pulau Karakelang Sulawesi Utara. Jurnal Penelitian Kehutanan Wallacea Volume 6(1), 61-71

Fan, H.P., M. Xie, W.W. Wang, S.S. Hou and W. Huang. 2008. Effect of dietary energy on growth performance and carcass quality of white growing pekin ducks from two to six weeks of age. Journal Poult.Sci. Volume 87:1162-1164.

Hernandez, F., J. Madrid, V. Garcia, J. Orengo and M.D. Megiaz. 2004.
Influence of two plants extracts on broilers performance, digestibility, and digestive organ size. Journal Poult.Sci. Volume 83:169-174.

Kiroh, H.J. 2009. Upaya domestikasi Tangkasi (Tarsius spectrum) melalui optimalisasi pemberian pakan secara gradual dalam penangkaran. Jurnal Ilmu-ilmu Hayati.

Lambert, F. R. 1997. Field assessment of the Conservation Status of Red-andBlue Lory. Eos histrio in Indonesia. IUCN. Gland, Switzerland and Bangkok, Thailand.

Mayasari, A. dan A. Suryawan. 2012. Peluang Konservasi Ex Situ Burung Sampiri (Eos histrio) Melalui Penangkaran. Ekspose Balai Penelitian Kehutanan Manado.

Nuraini., Sabrina dan S. A. Latif. 2012. Fermented product by Monacus purpureus in poultry diet effects on laying performance and egg quality. Pakistan Journal of Nutrition Volume 11: 507-510

Prijono, S.N., S. Handini. 2002. Memelihara, Menangkar dan Melatih Nuri. Penebar Swadaya. Jakarta. 110 hal. 